\title{
PERSONAL VALUE SYSTEM AS RELATED TO ANTI-MINORITY ATTITUDE IN MUSLIM STUDENTS OF RAJSHAHI UNIVERSITY, BANGLADESH
}

\author{
Noor Muhammad ${ }^{1} *$ and Md. Abdul Latif \\ Department of Psychology, University of Rajshahi, Rajshahi 6205, Bangladesh \\ ${ }^{1}$ Present address: Department of Psychology, Jagannath University, Dhaka 1100 \\ *Corresponding author; email: noor4salaphy@yahoo.com
}

\begin{abstract}
Relationships between personal values and anti-minority attitude in a group of 100 Muslim students of Rajshahi University were estimated using adapted Bengali versions of Allport-Vernon-Lindzey study of values and Levinson-Sanford Anti-Semitism scale. The relationships between anti-minority attitude and each of the Spranger's six values were computed to calculate the co-efficient of correlation between the scores on each of the six value scales and the scores on anti-minority attitude scale. Results show that a significant positive correlation exists between political and economical values and anti-minority attitude $(\mathrm{P}<0.01)$ while a significant negative correlation exists between theoretical, aesthetic, social and religious values and anti-minority attitude $(\mathrm{P}<0.01)$. For further analyzing the relationships that exists between Spranger's six values and antiminority attitude, the distribution of the latter was divided into four quarters and statistical comparisons were made among them on the basis of the scores of each value scale employing t-test. Statistical significant differences in values were found between the low ( $1^{\text {st }}$ quarter$)$ and high ( $4^{\text {th }}$ quarter) anti-minority attitude groups, indicating that high anti-minority attitude is dominated by political and economic values, while low anti-minority attitude is dominated by religious, theoretical, aesthetic and social values.
\end{abstract}

Key words: Personal value system, anti-minority attitude, prejudice, majority and minority groups, Muslim students, Rajshahi University

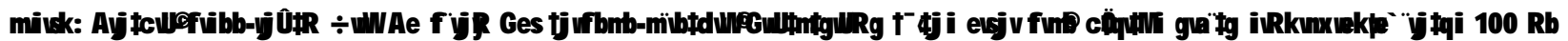

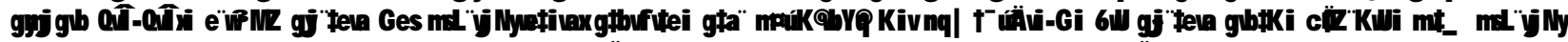

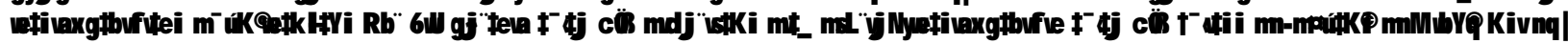

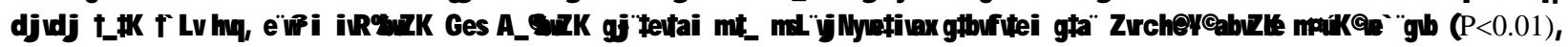

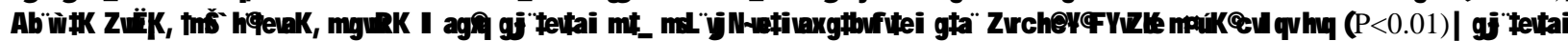

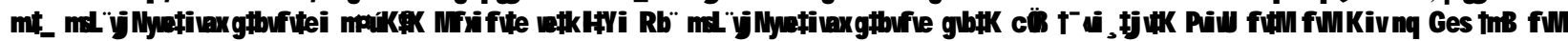

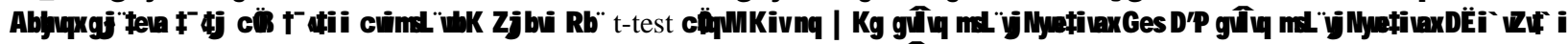

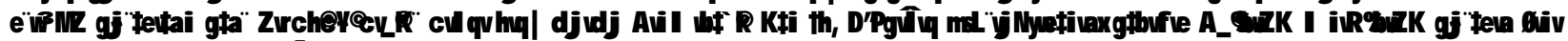

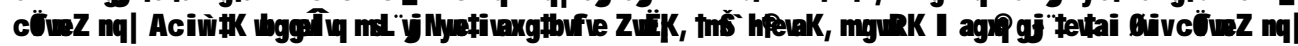

\section{Introduction}

A large number of studies have been conducted to compare the personality of so-called prejudiced individuals with the personality of so-called unprejudiced individuals in the last several decades. The comparison has resulted in a clearer picture of the personality structure of the prejudiced individual. It has also been shown that prejudice towards minority group tends to be only one of a constellation of personality factors that interact in a such a manner that the individual possessing the constellation might well be described as an "authoritarian personality" (Adorno et al. 1950). Examination of the studies of the "authoritarian personality" indicates that values may play an important role in such a personality pattern. Since the integration of personality, as Krech and Crutchfield (1948) suggested, "is mainly possible through the individual's system of values, ideas and ideology", the function of personal values would be crucial. Evans (1952) conducted a study in which he investigated the relationship between Anti-Semitism and Spranger's six values. He found a positive relationship of anti-minority attitudes with economic and political values and a negative correlation with social and aesthetic values. The investigator, however, did not find any significant relationship between AntiSemitism and theoretical value. But it has been found that theoretical people are intraceptive (Allport and Vernon 1931). Since intraception is related to tolerance, the findings of Evans (1952) seem to be consistent. The author, however, argued that some of the theoretical individuals might tend to be somewhat extraceptive. This raises the personality that both intraceptive and extraceptive individuals of his sample might score high on the theoretical value scale. Since intraception is related to tolerance and extraception is related to intolerance, it could materially reduce the significance of any negative relationship between Anti-Semitism and theoretical value. But the author did not provide with any experimental evidence in favour of his explanation. 
Evans also did not find any significant relationship between Anti-Semitism and religious value. In explaining these findings the author said that religious value subscale of Allport-Vernon-Lindzey study of values does not reliably differentiate between individuals who are religious in humanitarian sense and those in the narrow sense. As a result, the low prejudice group would score high in religious values sub-scale because of the presence of strong narrow type of religiousness. But since the author fails to provide with any empirical evidence in favour of his assumptions, it seems not to be acceptable to the present investigators. Rather present investigators think that some methodological weakness of Evans may be responsible for this ambiguity in his results. The authors feel that it is essential to repeat the study in order to draw a clear-cut conclusion about the relationship between personal values and anti-minority attitude. Moreover, in order to establish the generality of the findings of Evans, it is essential to study the relationship between personal values and anti-minority attitude in the context of other countries.

The present study, therefore, was an attempt to analyze and explain the relationship between personal values and anti-minority attitude in the context of Bangladesh with the following objectives: (a) To investigate whether there is any relationship between anti-minority attitudes of majority of Bangladesh and their personal values as measured by Allport-Vernon-Lindzey study of values; (b) To examine whether high anti-minority attitude is dominated by political and economic values; and (c) To examine whether low anti-minority attitude is dominated by religious, theoretical, aesthetic and social values. On the basis of the above discussion, the following hypotheses were formulated to test in the present study: (i) The presence of strong theoretical values in the personality structure of individual would be inconsistent with anti-minority attitude; (ii) The presence of strong economic values in the personality structure of individual would be consistent with antiminority attitude; (iii) The presence of strong political values would be inconsistent with anti-minority attitude; (iv) Strong social values and anti-minority attitude would be inconsistent; (v) Strong political values and anti-minority attitude would be consistent; (vi) Strong religious values and anti-minority attitude would be inconsistent; and (vii) Individuals relatively high in antiminority attitude are dominated by economic and political values; while individuals low in anti-minority attitude are dominated by aesthetic, theoretical, social and religious values.

\section{Materials and Methods}

Participants: A total of 100 Muslim students (50 male and 50 female) were used as respondents in the present study. The students were selected at random from the undergraduate levels of Rajshahi University. All the respondents came from the families of different socioeconomic background, whose age ranged from 18 to 22 years.

Measuring instruments: Adapted Bengali version of Allport-Vernon-Lindzey study of values (Latif 1991) and an adapted Bengali version of Levinson-Sanford Anti-Semitism scale (Muhammad 2001) were used to measure personal value system and anti-minority attitude, respectively. Allport et al. (1960) considered theoretical, economical, aesthetic, social, political and religious values, rationally determined by Spranger (1928). Earlier on, Levinson and Sanford (1944) developed their scale for measuring Anti-Semitism attitudes which contained 52 negative items only. The subject is asked to respond to each item by agreeing or disagreeing, and his responses were converted into scores in such a way that high score indicated a great amount of Anti-Semitism, and a low score the opposite. The procedure used for Anti-Semitism scale was to allow six choices of response for each item: Slight, moderate, or strong agreement and the same degrees of disagreement, with no middle or neutral categories. Each subject is to indicate the degree of his agreement by marking $+1,+2$ or +3 , disagreement by marking -1 , 2 or -3 . The responses were converted into scores by a uniform scoring system. All responses were scored as follows: $+1=5$ points, $+2=6$ points, $+3=7$ points, $-3=1$ point, $-2=2$ points and $-1=3$ points.

Procedures: The respondents were requested to come to the Department of Psychology, Rajshahi University, on a particular day. They were seated in a classroom and the test materials were supplied to each of them. They were asked to read the instructions printed in the first page of the test booklet. There was no time limit for answering the list but the respondents were instructed to complete it without wasting time. After the respondents had completed their task according to instructions, the booklets and the answer sheets were collected. Both the tests were administered to the respondents in a single seating.

\section{Results and Discussion}

The distribution of scores on anti-minority attitude scale was divided into four quarters. The first quarter included 25 percent of the sample who scored low (low prejudice group); the second quarter included the next 25 percent (medium prejudice group); the third quarter included the next 25 percent (medium high prejudice group); and the forth quarter included the highest scores on the scale (high prejudice group). The mean scores in each of these quarters were then calculated and a statistical comparison among the means was made by using Student's t-test. Seven hypotheses formulated to test the results of the present study are elaborated in the following paragraphs. 
First hypothesis: It was assumed that the theoretical value and anti-minority attitude are inconsistent i.e. there would exist a negative relationship between the scores on anti-minority attitude scale and the scores on theoretical value sub-scale. In agreement with this hypothesis, a negative correlation between the scores on anti-minority attitude scale and the theoretical value sub-scale was found (Table 1). The nature of the relationship between theoretical value and anti-minority attitude by virtue of a statistical comparison among the four quarters of antiminority attitude scores distribution presented in Tables 2 and 3 also indicates a negative relationship between the variables. Thus, the results of inter-quarter analysis provide further support to the hypothesis.

Second hypothesis: It was predicted that strong economic value would be congruent with anti-minority attitude, as a consequence, a positive relationship would exist between the scores on economic value sub-scale and anti-minority attitude scale. The results of the study confirm the hypothesis because there is a significant positive correlation between anti-minority attitude and economic value (Table 1). The nature of this relationship afforded further insight into these findings from Tables 2 and 3 that there is a positive relationship between economic value and anti-minority attitude. The results of inter quarter analysis, therefore, further support the hypothesis.

Third hypothesis: According to this hypothesis, strong aesthetic value and anti-minority attitude are inconsistent, suggesting that a negative relationship should exist between the score on anti-minority attitude scale and the score on aesthetic value sub-scale. Table 1 shows that there is a significant negative correlation between the scores on anti-minority attitude scale and aesthetic value sub-scale. Thus, the results confirm the hypothesis. A statistical comparison among the four quarters of anti-minority attitude scores distribution (Tables 2 and 3) also indicates a negative relationship between aesthetic value and anti-minority attitude, providing further support to the hypothesis.

Forth hypothesis: Since the presence of strong social value in the personality structure of individuals would be incongruent with anti-minority attitude, it was expected that there would exist a negative relationship between the scores on anti-minority attitude scale and the scores on social value sub-scale. The results of the study also confirm this hypothesis, because there is a significant negative correlation between the scores on anti-minority attitude scale and social value sub-scale (Table 1). A further support to the hypothesis is apparent from a statistical comparison among the four quarters of anti-minority attitude scores distribution (Tables 2 and 3), where a negative relationship exist between social value and anti-minority attitude.

Table 1. Correlations (r) between the scores on antiminority attitude scale and six values sub-scale.

\begin{tabular}{|c|c|c|}
\hline Variables compared & r-values & $\begin{array}{c}\text { Significance } \\
\text { levels (P) }\end{array}$ \\
\hline $\begin{array}{c}\text { Theoretical value and Anti- } \\
\text { minority attitude }\end{array}$ & -0.662 & $<0.001$ \\
\hline $\begin{array}{c}\text { Economic value and Anti- } \\
\text { minority attitude }\end{array}$ & 0.786 & $<0.001$ \\
\hline $\begin{array}{c}\text { Aesthetic value and Anti- } \\
\text { minority attitude }\end{array}$ & -0.671 & $<0.001$ \\
\hline $\begin{array}{c}\text { Social value and Anti- } \\
\text { minority attitude }\end{array}$ & -0.570 & $<0.001$ \\
\hline $\begin{array}{c}\text { Political value and Anti- } \\
\text { minority attitude }\end{array}$ & 0.796 & $<0.001$ \\
\hline $\begin{array}{c}\text { Religious value and Anti- } \\
\text { minority attitude }\end{array}$ & -0.460 & $<0.001$ \\
\hline
\end{tabular}

Table 2. Means and SD (standard deviations) of the value scores for the anti-minority attitude quarters (1= low, $2=$ medium low, 3= medium high, and 4= high).

\begin{tabular}{|c|c|c|c|c|}
\hline $\begin{array}{c}\text { Personal } \\
\text { values }\end{array}$ & Quarters & Numbers & Means & SD \\
\hline \multirow{4}{*}{ Theoretical } & 1 & 25 & 41.44 & 2.31 \\
\hline & 2 & 25 & 41.24 & 3.25 \\
\hline & 3 & 25 & 36.04 & 2.73 \\
\hline & 4 & 25 & 35.68 & 2.91 \\
\hline \multirow{4}{*}{ Economic } & 1 & 25 & 36.68 & 2.03 \\
\hline & 2 & 25 & 38.60 & 3.63 \\
\hline & 3 & 25 & 45.64 & 4.63 \\
\hline & 4 & 25 & 48.56 & 3.92 \\
\hline \multirow{4}{*}{ Aesthetic } & 1 & 25 & 41.36 & 1.60 \\
\hline & 2 & 25 & 38.92 & 3.35 \\
\hline & 3 & 25 & 36.16 & 3.01 \\
\hline & 4 & 25 & 35.36 & 2.74 \\
\hline \multirow{4}{*}{ Social } & 1 & 25 & 40.84 & 1.97 \\
\hline & 2 & 25 & 40.16 & 2.96 \\
\hline & 3 & 25 & 35.24 & 3.82 \\
\hline & 4 & 25 & 36.36 & 2.49 \\
\hline \multirow{4}{*}{ Political } & 1 & 25 & 36.76 & 2.18 \\
\hline & 2 & 25 & 39.60 & 4.15 \\
\hline & 3 & 25 & 46.72 & 3.38 \\
\hline & 4 & 25 & 46.60 & 2.59 \\
\hline \multirow{4}{*}{ Religious } & 1 & 25 & 42.92 & 2.90 \\
\hline & 2 & 25 & 41.56 & 3.67 \\
\hline & 3 & 25 & 40.52 & 4.02 \\
\hline & 4 & 25 & 37.04 & 2.75 \\
\hline
\end{tabular}


Table-3: Statistical comparisons of value scores of anti-minority attitude distribution in four quarters

\begin{tabular}{|c|c|c|c|c|c|}
\hline Values & Quarters & Mean differences & $\mathrm{SE}$ & t-values & Probabilities \\
\hline \multirow{6}{*}{ Theoretical } & $1 \& 4$ & 5.76 & 0.74 & 7.57 & 0.01 \\
\hline & $1 \& 3$ & 5.40 & 0.71 & 7.60 & 0.01 \\
\hline & $2 \& 4$ & 5.56 & 0.87 & 6.39 & 0.01 \\
\hline & $1 \& 2$ & 0.20 & 0.79 & 0.25 & ns \\
\hline & $2 \& 3$ & 5.20 & 0.84 & 6.19 & 0.01 \\
\hline & $3 \& 4$ & 0.36 & 0.79 & 0.46 & ns \\
\hline \multirow{6}{*}{ Economic } & $1 \& 4$ & 11.88 & 0.87 & 13.65 & 0.01 \\
\hline & $1 \& 3$ & 8.96 & 1.00 & 8.69 & 0.01 \\
\hline & $2 \& 4$ & 9.96 & 1.06 & 9.39 & 0.01 \\
\hline & $1 \& 2$ & 1.92 & 0.82 & 2.34 & 0.05 \\
\hline & $2 \& 3$ & 7.04 & 1.17 & 6.01 & 0.01 \\
\hline & $3 \& 4$ & 2.92 & 1.20 & 2.43 & 0.05 \\
\hline \multirow{6}{*}{ Aesthetic } & $1 \& 4$ & 0.60 & 0.63 & 9.52 & 0.01 \\
\hline & $1 \& 3$ & 5.20 & 0.68 & 7.65 & 0.01 \\
\hline & $2 \& 4$ & 3.56 & 0.86 & 4.14 & 0.01 \\
\hline & $1 \& 2$ & 2.44 & 0.73 & 3.34 & 0.01 \\
\hline & $2 \& 3$ & 2.76 & 0.89 & 3.10 & 0.01 \\
\hline & $3 \& 4$ & 0.80 & 0.81 & 0.98 & ns \\
\hline \multirow{6}{*}{ Social } & $1 \& 4$ & 4.48 & 0.63 & 7.10 & 0.01 \\
\hline & $1 \& 3$ & 5.60 & 0.85 & 6.58 & 0.01 \\
\hline & $2 \& 4$ & 3.80 & 0.77 & 4.90 & 0.01 \\
\hline & $1 \& 2$ & 0.68 & 0.70 & 0.97 & ns \\
\hline & $2 \& 3$ & 4.92 & 0.96 & 5.13 & 0.01 \\
\hline & $3 \& 4$ & 1.12 & 0.96 & 1.17 & ns \\
\hline \multirow{6}{*}{ Political } & $1 \& 4$ & 9.84 & 0.67 & 14.68 & 0.01 \\
\hline & $1 \& 3$ & 9.96 & 0.80 & 12.45 & 0.01 \\
\hline & $2 \& 4$ & 7.00 & 0.96 & 7.29 & 0.01 \\
\hline & $1 \& 2$ & 2.84 & 0.93 & 3.05 & 0.01 \\
\hline & $2 \& 3$ & 7.12 & 1.06 & 6.72 & 0.01 \\
\hline & $3 \& 4$ & 0.12 & 0.97 & 0.12 & ns \\
\hline \multirow{6}{*}{ Religious } & $1 \& 4$ & 5.88 & 0.79 & 7.44 & 0.01 \\
\hline & $1 \& 3$ & 2.40 & 0.98 & 2.45 & 0.01 \\
\hline & $2 \& 4$ & 4.52 & 0.91 & 4.97 & 0.01 \\
\hline & $1 \& 2$ & 1.36 & 0.92 & 1.48 & ns \\
\hline & $2 \& 3$ & 1.04 & 1.08 & 0.96 & ns \\
\hline & $3 \& 4$ & 3.48 & 0.96 & 3.63 & 0.01 \\
\hline
\end{tabular}

All t-values are at $48 \mathrm{df}$; ns= not significant

Fifth hypothesis: It was assumed that political value and anti-minority attitude are congruent, accordingly a positive relationship should exist between the score on anti-minority attitude scale and the score on political value sub-scale. Table 1 shows that there is indeed a significant positive correlation between the scores on anti-minority attitude scale and political value sub-scale, which confirms the hypothesis. The results of interquarter analysis provide further support to the hypothesis (Tables 2 and 3).

Sixth hypothesis: It was predicted that there would exist a negative relationship between the scores on anti-minority attitude scale and the scores on religious value sub-scale because, according to this hypothesis, the presence of strong religious value in the personality structure of individuals would be incongruent with anti-minority attitude. Table 1 shows that there exists a significant negative correlation between the scores on anti-minority attitude scale and religious value sub-scale. A statistical comparison among the four quarters of anti-minority attitude scores distribution (Tables 2 and 3) also shows a negative relationship between religious value and antiminority attitude. So, the results of inter-quarter analysis further support to the hypothesis.

Seventh hypothesis: It was assumed that individuals high in anti-minority attitude are dominated by political and economic values, while individuals relatively less in anti-minority are dominated by religious, theoretical, aesthetic and social values. This hypothesis concerning the value patterns presence in high and low prejudice 
groups was tested by transforming the scores made by each Ss on the six value sub-scales into rankings from 1 to 6 . The mean rankings for the values in each of the four quarters were then determined. These mean rankings were in turn converted to rankings from 1 to 6 . In each quarter, the value with the highest mean rank was ranked 1, the next highest 2 and so on. An order of dominance pattern of the six values in each of the four quarters was thus computed.

Table 4. Mean and SD (standard deviations) of the six value scores converted to ranking in anti-minority attitude distribution quarters $(1=$ low, $2=$ medium low, $3=$ medium high, and $4=$ high)

\begin{tabular}{|c|c|c|c|c|c|c|c|c|}
\hline \multirow{2}{*}{$\mathrm{N}$} & \multirow{2}{*}{ Qtr } & \multicolumn{7}{|c|}{ Values } \\
\cline { 3 - 9 } & & & $\mathrm{R}$ & $\mathrm{T}$ & $\mathrm{AE}$ & $\mathrm{S}$ & $\mathrm{P}$ & $\mathrm{E}$ \\
\hline \multirow{2}{*}{25} & \multirow{2}{*}{1} & Mean & 1.92 & 2.62 & 2.80 & 2.98 & 5.28 & 5.40 \\
\cline { 3 - 9 } & & $\mathrm{SD}$ & 1.28 & 1.32 & 1.08 & 1.21 & 0.58 & 0.64 \\
\hline \multirow{2}{*}{25} & \multirow{2}{*}{2} & Mean & 2.82 & 2.60 & 3.74 & 2.90 & 4.32 & 4.84 \\
\cline { 3 - 9 } & & SD & 1.42 & 1.58 & 1.49 & 1.30 & 1.64 & 1.35 \\
\hline \multirow{2}{*}{25} & \multirow{2}{*}{3} & Mean & 3.32 & 4.78 & 4.60 & 4.74 & 1.68 & 2.06 \\
\cline { 3 - 9 } & & SD & 1.26 & 0.94 & 0.90 & 0.16 & 1.07 & 1.28 \\
\hline \multirow{2}{*}{25} & \multirow{2}{*}{4} & Mean & 4.48 & 4.48 & 4.80 & 4.24 & 1.66 & 1.34 \\
\cline { 3 - 9 } & & SD & 1.08 & 1.08 & 1.05 & 0.98 & 0.42 & 0.42 \\
\hline
\end{tabular}

$\mathrm{R}=$ Religious, $\mathrm{T}=$ Theoretical, $\mathrm{AE}=$ Aesthetic, $\mathrm{S}=$ Social, $\mathrm{P}=$ Political, $\mathrm{E}=$ Economic

Data presented in Table 4 show that the dominant values in the high prejudice group are economic and political values, while the dominant values in low prejudice are religious, theoretical, aesthetic and social values which confirm the hypothesis. Thus the results of the study suggest that there is positive relationship between political and economic values and antiminority attitude, while there is a negative relationship between theoretical, aesthetic, social and religious values and anti-minority attitude. These findings appear to fit the theoretical model of realistic conflict theory, which states that prejudice is the outcome of direct competition over valued but limited resources (Hilton et al. 1989, Brown and Williams 1984). In this view the things we value most in life are limited and people must compete with others to obtain what they consider their fair share. When they perceive that members of minority groups prevent attaining those higher standards, they will view those minorities in an increasingly hostile manner.

In explaining the results of the present study it can be argued that the economic and political persons are competitive than the others. As a result, these persons become more prejudiced towards the minority group, subsequently they grow more and more political or economic. The theoretical, aesthetic, social and religious persons, on the other hand, are less competitive than the political and economic persons and therefore less prejudiced towards minority, as they grow more and more aesthetic or theoretical or social or religious.

\section{Conclusion}

Following conclusion may be drawn from the present investigation: (i) Anti-minority is positively related to political and economical values; (ii) Anti-minority attitude is negatively related to theoretical, aesthetic, social and religious values; and (iii) The high antiminority attitude is dominated by political and economic values, whereas the less anti-minority attitude is dominated by religious, theoretical, aesthetic, and social values.

\section{References}

Adorno TW, Frenkel-Brunswik, E., Levinson DJ and Sanford RN. 1950. The Authoritarian Personality. Harper, New York.

Allport GW and Vernon PE. 1931. A Study of Values. Houghton Mifflin Co,, Boston.

Allport GW and Kramer D. 1996. Some roots of prejudice. $J$. Social Psychol. 22: 9-39.

Allport GW, Vernon PE and Lindzey G. 1960. Manual of Study of Values ( $3^{\text {rd }}$ edn). Houghton Mifflin Co., Boston.

Brown RJ and Williams J. 1984. Group Identification: The same thing to all people? Human Relations 37: 547-564.

Evans RI. 1952. Personal Values as factors in Anti-Semitism. J. Abnormal Social Psychol. 47: 749-756.

Hartley E. 1946. Problems in Prejudice. Kings Crown Press, New York.

Hilton A, Potvin L and Sachdev I. 1989. Ethnic relations in rental housing: A social psychological approach. Canadian J. Behav. Sci. 21: 121-131.

Krech D and Crutchfield R. 1984. Theory and Problems of Social Psychology. McGraw-Hill, New York.

Latif M A. 1991. Adaptation of Allport-Vernon-Lindzey Study of Values for use in Bangladesh. Bangladesh $J$. Psychol. 12: 24-30.

Levinson DJ and Sanford RN. 1944. A scale for measurement of Anti-Semitism. J. Psychol. 17: 339-370.

Muhammad N. 2001. Personal Value System and AntiMinority Attitude. Unpubl. M.Sc. Thesis, Department of Psychology, University of Rajshahi.

Spranger E. 1928. Types of Men. Translated from the $5^{\text {th }}$ German edition of Lebens for Emn by PJ Pigors. Hall: Max Niemeyer Verlag, American Agent: StechertHafner, Inc. New York.

Manuscript received on 15 September 2010 and revised on 18 January 2011 